\title{
MANCHA FISIOLÓGICADOMAMÃO 'FORMOSA': RELAÇÕES COM O POTENCIAL HÍDRICO DO SOLO, O TEOR DE SÓLIDOS SOLÚVEIS TOTAIS DO LÁTEX E AS VARIÁVEIS DO CLIMA
}

\author{
Skin freckles on 'Formosa' papaya: relationships with soil water potential, \\ total soluble solids of latex and climate variables
}

Fabrício de Oliveira Reis ${ }^{1}$, Eliemar Campostrini $^{2}$, Alena Torres Netto ${ }^{3}$

\begin{abstract}
RESUMO
Em várias regiões produtoras de mamão do Brasil, tem sido observado um distúrbio fisiológico nos frutos denominado de Mancha Fisiológica do Mamão (MFM). Tal distúrbio pode causar significativos prejuízos ao produtor, uma vez que pode comprometer a qualidade do fruto da espécie. Procurou-se buscar, neste trabalho, possíveis relações entre a incidência da MFM, o potencial hídrico do solo, o teor de sólidos solúveis no látex, a amplitude térmica e o déficit de pressão de vapor do ar. Para tanto, num plantio comercial localizado na cidade de São Francisco do Itabapoana - RJ, foram monitorados o déficit de pressão de vapor do ar, o potencial hídrico do solo, o teor de sólidos solúveis no látex dos frutos em duas faces do fruto (face próxima ao tronco e face oposta ao tronco) e a amplitude térmica do ar. Foi verificado que nos meses que antecederam a época de maior incidência da MFM, o déficit hídrico do solo acentuado (média diária -113,6kPa nos meses de abril a julho), em associação com menores demandas evaporativas do ar (média diária nos meses de abril a julho $0,6 \mathrm{kPa}$ ) e uma amplitude térmica média de $11,3^{\circ} \mathrm{C}$ nessas mesmas épocas, contribuiu para a maior incidência da MFM, nos meses julho a outubro.
\end{abstract}

Termos para indexação: Carica papaya L., distúrbio fisiológico, sazonalidade.

\section{ABSTRACT}

In some papaya producing regions in Brazil, it was observed a physiological disturb in the fruits called Skin Freckles (SF). Such disturb may cause significant damages to crops, since it may affect the quality of the fruits. This work aimed to search possible relationship among the SF incidence, the soil water potential, the soluble solid content in the latex, the thermal amplitude and the air vapor pressure deficit. These studies were carried out in a commercial orchard located in the town of São Francisco de Itabapoana RJ, where some characteristics were monitored including the air vapor pressure deficit, the soil water potential, the soluble solid content in the latex in two faces of the fruit (the face close to the trunk and the opposing face to the trunk) and the air thermal amplitude. One verified that in the months that preceeded the period of higher incidence of the SF, the soil water deficit increased (daily average of $-113,6 \mathrm{kPa}$ from April to July), in association with smaller air evaporative demands (daily average of $0,6 \mathrm{kPa}$ from April to July) and a thermal amplitude average of $11,3^{\circ} \mathrm{C}$ in these same periods contributed for the higher incidence of the SF in the months between July and October.

Index terms: Carica papaya L., physiological disturb, seasonality.

(Recebido em 4 de julho de 2007 e aprovado em 7 de março de 2008)

\section{INTRODUÇÃO}

Recentemente, na região Norte Fluminense, um grande incentivo tem sido dado à fruticultura tropical irrigada. Nessa região, os estudos têm demonstrado o elevado potencial produtivo e de comercialização das fruteiras tropicais (FIRJAN, 1998). Dentre as culturas com grande potencial de cultivo para o Norte Fluminense, se destaca a cultura do mamoeiro. Entretanto, no Brasil e nessa região fluminense, a cultura tem apresentado alguns problemas, entre os quais, pode-se relatar a "Mancha
Fisiológica do Mamão" (MFM) (CAMPOSTRINI et al., 2005; LIMA, 2003). As evidências levam a crer que se trata de um distúrbio fisiológico (KAISER et al., 1996). Normalmente, esse distúrbio ocorre no fruto e a maior incidência ocorre nos meses mais frios e secos do ano. Essa anomalia tem causado sérios prejuízos à cultura, devido à desvalorização comercial do fruto dessa espécie, no aspecto estético externo (KAISER et al., 1996).

A presença da MFM é uma das maiores limitações para venda do fruto para o mercado externo, que exige um

${ }^{1}$ Engenheiro Agrônomo, Doutor em Produção Vegetal - Departamento de Biologia Vegetal-Botânia - Universidade Federal do Espírito Santo - Av. Fernando Ferrari, 514 - 29075-910 - Vitória, ES - fareoli@gmail.com

Engenheiro Agrônomo, Doutor em Produção Vegetal, Professor Associado - Centro de Ciências e Tecnologias Agropecuárias/CCTA - Setor de Fisiologia Vegetal/SFV - Avenida Alberto Lamego, 2000 - Horto - 28015-620 - Campos dos Goytacazes, RJ - campost@uenf.br

${ }^{3}$ Engenheira Agrônoma, Doutora em Produção Vegetal - Centro de Ciências e Tecnologias Agropecuárias/CCTA - Setor de Fisiologia Vegetal/SFV Avenida Alberto Lamego, 2000 - Horto - 28015-620 - Campos dos Goytacazes, RJ - alenanetto@msn.com 
fruto livre de manchas (KAISER et al., 1996). Segundo Reyes \& Paull (1994), em relação à casca do fruto a MFM se caracteriza pela presença de manchas de coloração escura, e se localiza na superfície dos órgãos exposta à radiação solar direta. No caso do mamoeiro do grupo 'Formosa' e no estádio mais avançado desse distúrbio, observações práticas mostram que as manchas apresentam elevado diâmetro e com um aspecto de desidratação intensa e com rachaduras. Em mamoeiros do grupo Solo, a maior incidência da MFM aconteceu em frutos que estavam na metade do crescimento final (40 dias após a antese) (REYES \& PAULL, 1994).

As causas e os fatores que influenciam a ocorrência da MFM são desconhecidos. No entanto, sabe-se que a incidência da mancha não está relacionada com infecções bacterianas ou por fungos (REYES \& PAULL 1994), e sim influenciadas por fatores genéticos e ambientais (KAISER et al., 1996).

Alguns fatores do ambiente como temperatura e umidade relativa, expressos por meio do déficit de pressão de vapor do ar podem ter uma ação importante sobre alguns distúrbios fisiológicos em frutos de algumas espécies (BERTIN et al., 2000; CREASY, 1980; LEONARDI et al., 2000). Em tomateiro, altas umidades relativas proporcionaram maiores rachaduras no fruto, distúrbio conhecido como "cracking". Resultados semelhantes foram observados por Bertin et al. (2000). Segundo Ohta et al. (1997) a rachadura no fruto ocorre quando a extensão da epiderme excede a elasticidade desse conjunto de células externas ao fruto, devido à pressão de turgescência interna, principalmente durante os períodos de rápida expansão do fruto.

A MFM foi associada positivamente com os estádios finais de crescimento do fruto (intensa taxa de crescimento), com a espessura da cutícula e com teor de sólidos solúveis do látex (REYES \& PAULL, 1994). Segundo esses autores, nos frutos de mamoeiro com maturação mais avançada, que tiveram uma maior espessura de cutícula, apresentaram maior número de manchas que os frutos jovens. Esses últimos apresentaram uma menor espessura de cutícula. Segundo Reyes \& Paull (1994), nos frutos com maturação mais avançada e que possuem cutícula mais espessa, essa cutícula, durante o crescimento do fruto, pode estar sendo submetida a uma grande força relacionada à pressão de turgescência. Uma vez que a área em torno do estômato pode ser uma região mais frágil, por ação dos fatores do ambiente como luz, temperatura e àgua no ar, nesses locais do complexo estomático, pode haver uma ruptura dos vasos laticíferos. De fato, segundo Kaiser et al. (1996), as manchas foram associadas à cavidade estomática, uma vez que densidade estomática da epiderme de frutos de mamão está em torno de 2340 estômatos $\mathrm{cm}^{-2}$ (PAULL \& CHEN, 1989). Ainda, os autores relatam que a elevada precipitação pluviométrica pode aumentar a pressão de turgescência dos vasos laticíferos e, dessa maneira, pode aumentar a área de ruptura desses vasos nos frutos mais desenvolvidos.

Em seringueira, a exudação do látex, que pode atingir uma pressão de 1,5 MPa, é extremamente afetada pelo estado hídrico do ar e do solo (RAGHAVENDRA, 1991). Maiores pressões estão relacionadas ao melhor estado hídrico da planta. Em função do estado hídrico do solo, do ar e da planta, durante o dia, a variação na pressão de turgescência em relação à altura da árvore, é bem elevada

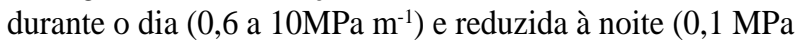
$\mathrm{m}^{-1}$ ). Segundo Raghavendra (1991), em seringueira, a maior produção de látex acontece antes do nascer do sol, apresenta um máximo de produção pela manhã e decresce acentuadamente durante o dia. Como exemplo, a produção de látex às 13:00 é 70\% do máximo (PAARDEKOOPER \& SOOKMARK, 1969). Nessa espécie, o decréscimo na exsudação do látex durante o dia deve-se à acentuada redução na pressão de turgescência dos vasos laticíferos, causada pela intensa perda de água por meio da transpiração (BUTTERY \& BOATMAN, 1966). Segundo esses autores a pressão de turgescência dos vasos foi positivamente correlacionada com a umidade relativa, e negativamente correlacionada com a temperatura, evaporação, déficit hídrico e abertura estomática.

Com relação ao teor de sólidos solúveis no látex, Reyes \& Paull (1994) mostraram que os frutos de maior tamanho apresentaram maior número de MFM, maior teor de sólidos solúveis no látex, ou seja, o látex apresentou maior potencial osmótico. Os autores relataram que o maior potencial osmótico no látex dos frutos com maturação mais avançada, proporcionou maior turgescência nos vasos laticíferos. Essa maior pressão estaria associada à ruptura desses vasos, e tal ruptura dos vasos seria exteriorizada na forma de manchas, denominadas MFM, ou "skin freckles", em inglês. Segundo os autores, temperaturas altas e baixas, dois meses antes da colheita dos frutos elevaram a incidência de manchas, que foram relacionadas à variações, no estado hídrico da planta.

No trabalho publicado por Campostrini et al. (2005), na região Norte Fluminense, foi verificado que a incidência da MFM foi maior no mês de outubro, e que as variáveis temperatura e amplitude térmica nos meses de junho, julho e agosto, que antecederam o mês de maior ocorrência, foram as mais relacionadas com a ocorrência da MFM. Ou seja, maiores amplitudes nos meses supracitados promoveram 
maior incidência da MFM. No trabalho publicado por Campostrini et al. (2005), observou-se que a incidência das manchas foi maior na face do fruto exposta à radiação solar, bem como na região mediana do fruto

No caso da espécie $C$. papaya L., a presença de sólidos solúveis no látex pode resultar em um menor potencial de água, o que pode conferir em uma maior pressão hidrostática, dependendo da disponibilidade hídrica da planta. A maior pressão hidrostática poderá estar relacionada a uma maior pressão de turgescência dos vasos laticíferos, podendo resultar no extravasamento do látex, entre as células do tecido do fruto. O contato das substâncias constituintes do látex com o tecido desse órgão podem causar uma necrose, que é exteriorizada como uma mancha denominada MFM. Vale salientar que o látex do fruto do mamoeiro é uma mistura complexa de compostos químicos com diversas atividades, estando associados ao sistema de defesa da planta contra o ataque de pragas e herbívoros (ELMOUSSAOUI et al., 2001).

Os estudos relacionados à morfologia, à ultraestrutura e à fisiologia sugerem que as manchas são derivadas no látex (KAISER et al., 1996). Estes autores mostraram que, nas manchas, foram encontradas proteínas com o mesmo peso molecular das proteínas presentes no látex, evidenciando a forte relação entre a mancha e o látex. Tais proteínas apresentavam predominantemente 29 a 44kDa. Segundo Kaiser et al. (1996), uma possível estratégia para a redução da incidência da MFM, seria reduzir a pressão de turgescência dos frutos, por meio da limitação da irrigação nos meses mais frios (assim como no Brasil, na África do Sul, estes meses apresentam maior incidência da MFM), período este em que se tem maiores flutuações na temperatura do ar, uma vez que amplitudes térmicas elevadas estão fortemente associadas à MFM (CAMPOSTRINI et al., 2005; KAISER et al., 1996). Dowton (1981) relata que em plantas de Nerium oleander, cultivadas em duas condições controladas de temperatura do ar (20/ $15^{\circ} \mathrm{C}$ e $45 / 32^{\circ} \mathrm{C}$, dia/noite) e sem limitação de água no sistema radicular, as plantas cultivadas nas condições $20 / 15^{\circ} \mathrm{C}$ apresentaram valores de potencial de turgescência em

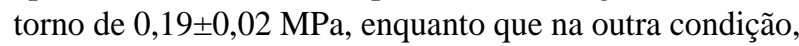
as plantas apresentaram valores de $\psi_{\mathrm{p}}=0,08 \mathrm{MPa}$. Ou seja, uma amplitude $15^{\circ} \mathrm{C}$ proporcionou maior pressão de turgescência do que uma amplitude de $13^{\circ} \mathrm{C}$.

Uma vez que o estado hídrico da planta e o teor de sólidos solúveis no látex podem estar associados à incidência da MFM, como foi proposto por Reyes \& Paull (1994), objetivou-se, neste trabalho, obter possíveis relações entre a Mancha Fisiológica do Mamoeiro (Carica papaya L.), do grupo 'Formosa', na Região Norte Fluminense, com o teor de sólidos solúveis do látex, o potencial hídrico do solo e o déficit de pressão de vapor do ar.

\section{MATERIAL E MÉTODOS}

\section{Material vegetal e condições de cultivo}

Durante um ano (08/10/02 a 08/10/03), foram efetuados estudos em uma área de plantio comercial de mamoeiro em fase de produção do grupo 'Formosa', localizada no município de São Francisco de Itabapoana/ RJ (latitude de $21^{\circ} 27^{\prime} \mathrm{S}$, longitude de $41^{\circ} 15^{\prime} \mathrm{O}$ e com altitude de $12 \mathrm{~m}$ acima do nível do mar). O espaçamento adotado foi de 3,8 x 2,0m e o solo onde foram cultivadas as plantas era do tipo Argissolo Amarelo. A lavoura foi irrigada por meio do sistema do tipo pivô central, não havendo turno de rega definido. Esse manejo foi adotado pelo produtor para a produção comercial de frutos.

\section{Variável climática tensão de água no solo}

$\mathrm{O}$ déficit de pressão de vapor do ar $\left(\mathrm{DPV}_{\mathrm{ar}}\right)$ do local onde foi realizado o experimento foi calculado segundo a equação proposta por (JONES, 1992):

$$
\mathrm{DPV}_{\mathrm{ar}}(\mathrm{kPa})=0,61137 \mathrm{e}^{\mathrm{t} *}(1-\mathrm{UR} / 100)
$$

em que t é calculado pela equação:

$$
\mathrm{t}=17,502 *\left(\mathrm{~T}_{\mathrm{ar}}\right) /\left(240,97+\mathrm{T}_{\mathrm{ar}}\right)
$$

UR é a umidade relativa do ar e $\mathrm{T}_{\mathrm{ar}}$ é a temperatura do ar.

Ambas as variáveis foram obtidas por meio de sensores automáticos de coleta de dados, modelo WatchDog 450, Spectrum Technologies, Illinois, U.S.A. Tais sensores foram instalados dentro da área de plantio, localizados dentro de abrigos à uma altura de $1 \mathrm{~m}$, em relação ao nível do solo. $\mathrm{O}$ potencial hídrico do solo $\left(\psi_{\text {solo }}, \mathrm{kPa}\right)$ foi obtido por meio do uso de um sensor Watermark Soil, acoplado a um coletor de dados modelo WatchDog 450, Spectrum Technologies, Illinois, U.S.A. Os sensores de umidade do solo foram colocados a uma profundidade de $0,30 \mathrm{~m}$, e $0,40 \mathrm{~m}$ de distância do tronco. Ao todo, foram utilizados quatro sensores (dois sensores por planta). Tanto para as variáveis de temperatura e umidade relativa do ar, como para a tensão de água do solo, os dados foram armazenados em um datalogger a cada hora.

\section{Quantificação da "Mancha Fisiológica do Mamão" e determinação do teor de sólidos solúveis no látex}

Durante o período de um ano, nos meses de janeiro, março, abril, julho, agosto, setembro e outubro, foi efetuada 
a quantificação da Mancha Fisiológica. Para tanto, em cada mês, foram coletados frutos de 30 plantas, os quais apresentavam quatro faixas amareladas na extremidade distal. Na contagem da incidência da MFM, foi utilizada uma tela transparente ("tipo folha de transparência para retroprojetor") de $75 \times 75 \mathrm{~mm}$ contendo 900 quadrículas de $6,25 \mathrm{~mm}^{2}$ cada. Em média, a área da tela correspondia entre 6 a 10\% da área total do fruto do mamoeiro 'Formosa'. Essa tela foi centralizada num ponto distante $10 \mathrm{~cm}$ da parte distal do epicarpo exposto e não-exposto à incidência solar direta (área de maior incidência da MFM) e foi feita a contagem do número de quadrículas ocupadas pela Mancha Fisiológica. Após a contagem do número de quadrículas, foram calculadas as frequiências acumuladas com base na seguinte equação:

$$
\mathrm{F}=\mathrm{m} /(\mathrm{n}+1)
$$

Em que:

$\mathrm{F}=$ Freqüência;

m=Número de ordem;

$\mathrm{n}=$ Número de dados

Nas mesmas áreas onde se efetuou a contagem da mancha, foi feita a estimativa do teor de sólidos solúveis ( ${ }^{\circ}$ BRIX) por meio de um refratômetro eletrônico (modelo RF80, Spectrum Technologies, Illinois, USA). Tal medição foi feita efetuando-se leves perfurações na epiderme, de modo a propiciar a exsudação do látex. Rapidamente, antes que houvesse o processo de coagulação, o látex era posto no refratômetro, para assim efetuar a medição do ${ }^{\circ}$ BRIX.

Os dados foram coletados seguindo um modelo experimental inteiramente casualizado, com 30 repetições e a análise dos dados foi feita usando o erro padrão em relação à média dos dados.

\section{RESULTADOS E DISCUSSÃO}

Neste estudo, foi verificado que, em comparação aos meses de janeiro, março e abril, os meses de julho, agosto, setembro e outubro de 2003 foram os meses com maior incidência da MFM (Figura 1). Tais meses apresentaram os maiores números de quadrículas preenchidas com a MFM. O mês de maio apresentou uma incidência intermediária (dados não-mostrados). O mês de julho foi o mês que apresentou a maior incidência da MFM. Lima (2003) e Ueno et al. (2002) observaram resultados semelhantes em frutos de mamoeiro produzidos nos municípios de São Francisco do Itabapoana/ RJ e Luiz Eduardo Magalhães/BA. Na África do Sul, Kaiser et al. (1996) relataram que a incidência da MFM foi maior nos meses mais frios, que correspondem no hemisfério sul aos meses de julho, agosto, setembro e outubro.

Numa comparação entre a Figura 1 e a Figura 2, observou-se que o potencial hídrico do solo nos meses que antecederam (abril/03 a julho/03) a época de maior incidência (agosto/03 a outubro/03) apresentou um valor médio de $-113,6 \mathrm{kPa}$, enquanto que, nos meses que antecederam (outubro/02 a dezembro/02) a época de menor incidência da MFM (janeiro/03 a julho/03), o valor médio desta variável foi de $50,1 \mathrm{kPa}$. Este fato pode mostrar que o período de déficit hídrico no solo nos meses de abril a julho $(-113,6 \mathrm{kPa})$, pode ter causado variações em maior intensidade no estado hídrico da planta, causando assim uma maior incidência da MFM.

Possivelmente, a permanência do solo em um período longo de limitação hídrica, e, logo após, o potencial hídrico reduzindo ainda mais (final de julho), pode ter promovido um incremento acentuado na pressão de turgescência dos vasos laticíferos, causando assim o extravasamento do látex e, dessa maneira, originando a MFM. O maior período com limitação hídrica do solo pode ter atuado em ação conjunta com uma maior amplitude térmica $\left(11,3^{\circ} \mathrm{C}\right)$ e com um menor $\operatorname{DPV}_{\text {ar }}(0,6 \mathrm{kPa})$ (Figura 2), o que poderia ter causado a MFM, nos meses supracitados. Possivelmente, a ação desses fatores poderiam ter causado uma maior amplitude na pressão de turgescência e assim, ser esse o fator desencadeador do processo. Campostrini et al. (2005) mostraram que a amplitude térmica elevada nos três meses que antecederam ao mês de maior incidência da MFM (setembro) foi o fator mais relacionado com a MFM no norte fluminense, o que pode mostrar que essa variável climatológica pode contribuir em alguma intensidade na incidência da MFM na presente trabalho.

Nos meses de maior deficiência hídrica, a ação do déficit hídrico do solo sobre a incidência da MFM foi mostrada nos frutos colhidos nos meses de julho a outubro de 2003. Em estudos feitos no cerrado baiano, Ueno et al. (2002) verificaram que pomares com déficits hídricos apresentaram maiores incidências da MFM. Possivelmente, na época de déficit hídrico, os vasos laticíferos apresentaram uma maior variação na pressão de turgescência.

Aloni et al. (1998) verificaram que a limitação da transpiração noturna, por meio da alta umidade relativa ou da baixa temperatura do ar, aumentou a pressão de turgescência nas células do pericarpo do fruto e, conseqüentemente, causou rachaduras em frutos de pimentão. Nos meses de abril a julho, o valor do DPV ar foi menor $(0,6 \mathrm{kPa})$, em relação aos meses de outubro a dezembro $(0,8 \mathrm{kPa})$. Possivelmente, o menor valor dessa variável possa ter contribuído de alguma forma para desencadear a MFM.

Os valores do ${ }^{\circ}$ Brix do látex, medidos nas duas faces do fruto (face exposta e não-exposta aos raios solares), não se mostraram relacionados com a incidência da MFM (Figura 3). Resultados contraditórios foram obtidos por Reyes \& Paull (1994), que encontraram uma relação positiva entre o teor de sólidos solúveis do látex com a incidência da MFM. 
$12 / 01 / 03$

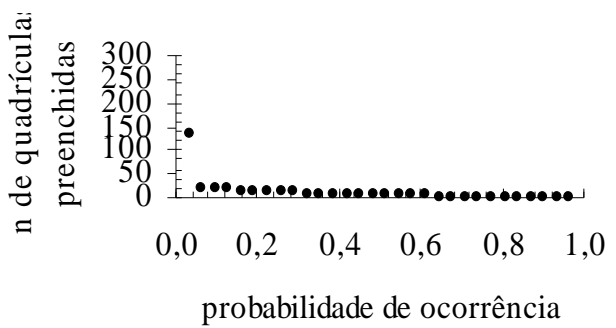

$15 / 04 / 03$

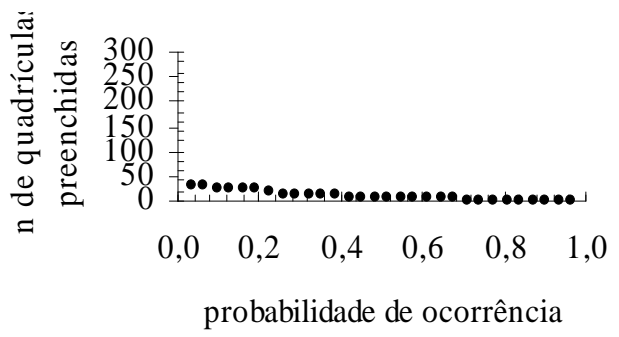

21/08/03

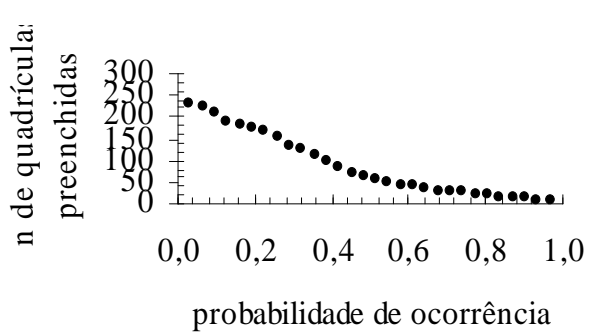

07/03/03

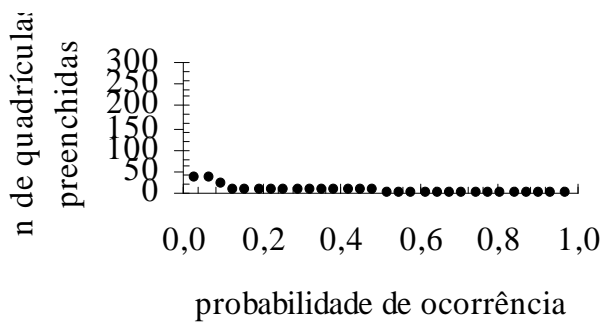

$16 / 07 / 03$

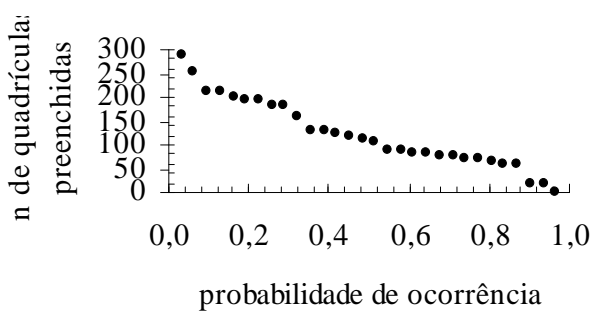

$12 / 09 / 03$

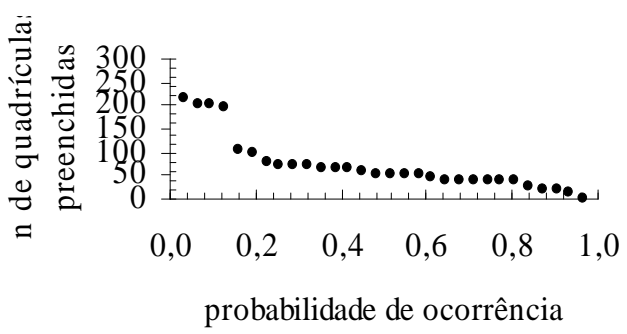

08/10/03

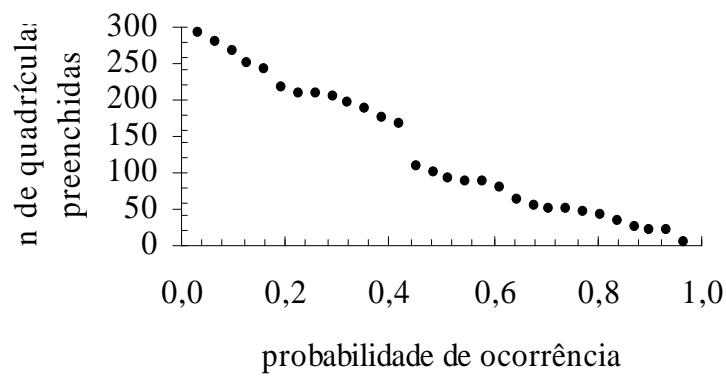

Figura 1 - Quantificação da intensidade da Mancha Fisiológica do Mamão (MFM), em mamoeiro do grupo 'Formosa'. Foram utilizados 30 frutos em cada época de contagem. Os frutos foram coletados de 30 plantas, no município de São Francisco do Itabapoana/RJ. 

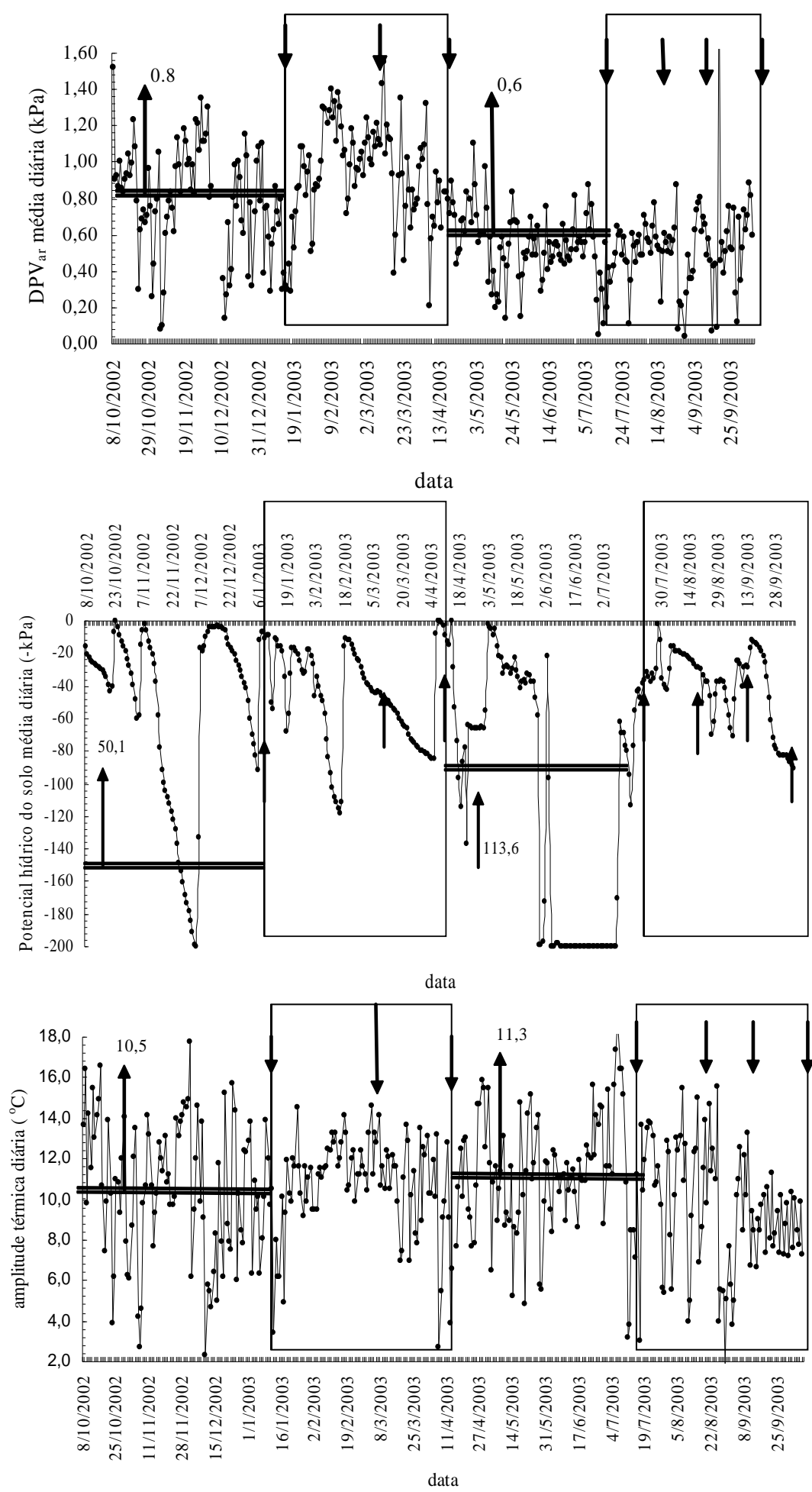

Figura 2 - Déficit de pressão de vapor do ar (DPV ${ }_{\mathrm{ar}}$ ), potencial hídrico do solo e amplitude térmica do ar, coletados diariamente. As setas para baixo indicam as datas de determinação da contagem da MFM. As setas para cima indicam as médias dos valores no período. Os quadrados da direita referem-se à época de maior incidência da MFM. 


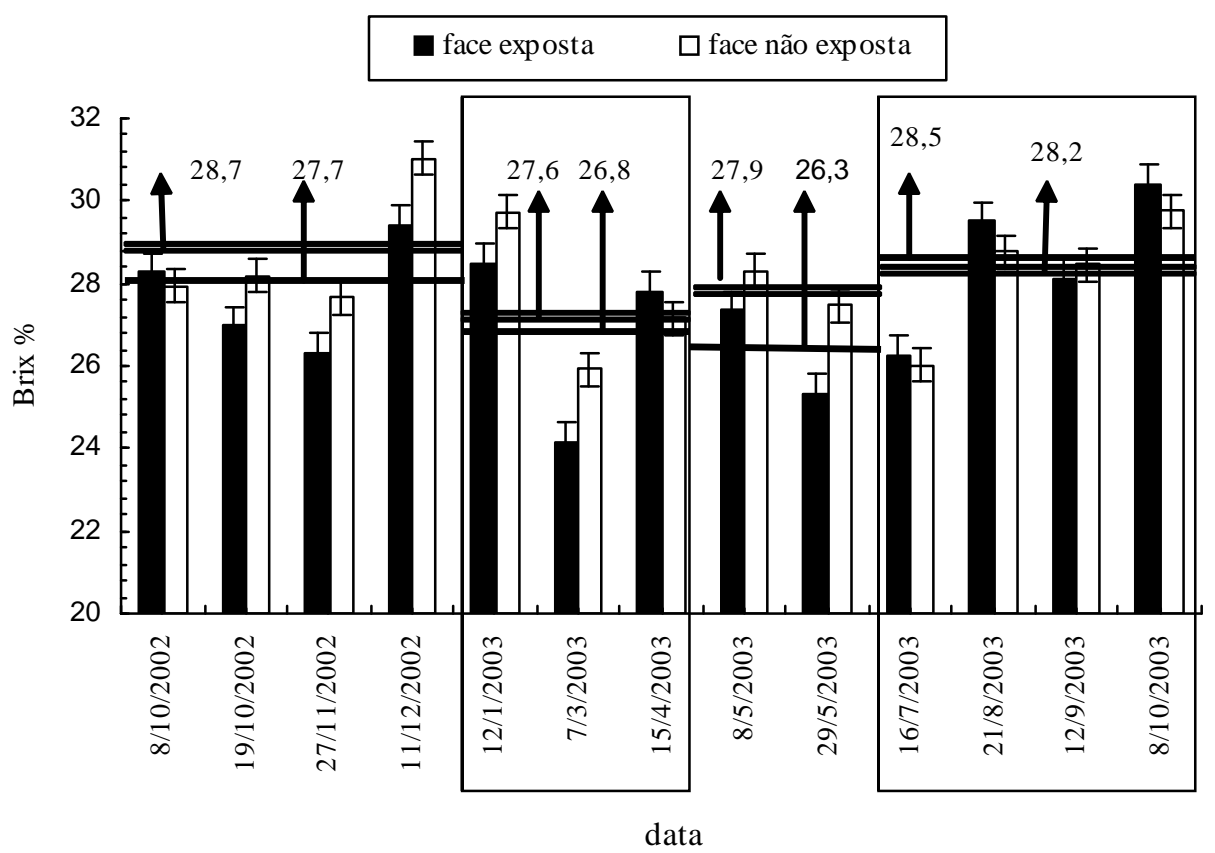

Figura 3 - Valores do teor de sólidos solúveis totais do látex, na face exposta e não-exposta à radiação solar, nos frutos de mamoeiro 'Formosa'. Os dados são referentes à média de 30 frutos. As setas indicam as médias em cada época. As barras correspondem ao erro padrão da média. O quadrado da direita refere-se à época de maior incidência da MFM.

\section{CONCLUSÃO}

Nos meses que antecederam a época de maior incidência da MFM, o déficit hídrico do solo acentuado, em associação com menores demandas evaporativas do ar e uma amplitude térmica média de $11,3^{\circ} \mathrm{C}$ contribuiu para a maior incidência da MFM nos meses de julho, agosto, setembro e outubro de 2003. Futuros trabalhos deverão ser desenvolvidos objetivando-se determinar, em diferentes épocas, as possíveis alterações na pressão de turgescência dos vasos laticíferos para, assim, buscar as verdadeiras causas desse distúrbio fisiológico.

\section{AGRADECIMENTOS}

À Financiadora de Estudos e Projetos (FINEP), ao Sr. Afonso Torezzani, produtor rural, à Fundação Carlos Chagas de Apoio à Pesquisa, no Estado do Rio de Janeiro (FAPERJ) e ao Professor Eder Dutra Resende, do Laboratório de Tecnologia de Alimentos, por ter emprestado gentilmente o refratômetro.

\section{REFERÊNCIAS BIBLIOGRÁFICAS}

ALONI, B.; KARNI, L.; RYLSKI, I.; COHEN, Y.; LEE, Y.; FUCHS, M.; MORESHET, S.; YAO, C. Cuticular cracking in pepper fruit I: effects of night temperature and humidity.
Journal of Horticulture Science and Biotechnology, Coventry, v. 73, p. 743-749, 1998.

BERTIN, N.; GUICHARD, S.; LEONARDI, C.; LONGUENESSE, J. J.; LANGLOIS, D.; NAVEZ, B. Seasonal evolution of the quality of fresh glasshouse tomatoes under mediterranean conditions, as affected by air vapour pressure deficit and plant fruit load. Annals of Botany, Bristol, v. 85, p. 741-750, 2000.

BUTTERY, B. R.; BOATMAN, S. G. Manometric measurement of turgor pressures in laticiferous phloem tissues. Journal Experimental Botany, Lancaster, v. 17, p. 283-296, 1966.

CAMPOSTRINI, E.; LIMA, H. C.; OLIVEIRA, J. G.; MONNERAT, P. H.; MARINHO, C. S. Teores de Ca e variáveis meteorológicas: relações com a mancha fisiológica do mamão no norte fluminense. Bragantia, Campinas, v. 64, p. 601-613, 2005.

CREASY, L. L. The correlation of weather parameters with russet of 'Golden Delicious' apples under orchard conditions. Journal American Society Horticultural Science, Alexandria, v. 105, p. 735-738, 1980. 
DOWNTON, W. J. S. Water relations of laticifers in Nerium oleander. Australian Journal Plant Physiology, Sidney, v. 8, p. 329-334, 1981.

EL-MOUSSAOUI, A.; NIJS, M.; PAUL, C.; WINTJENS, R.; VICENTELLI, J.; AZARKAN, M.; LOOZE, Y. Revisiting the enzymes stored in the laticifers of Carica papaya in the context of their possible participation in the plant defence mechanism. Cellular and Molecular Life Sciences, Paris, v. 58, p. 556-570, 2001.

FIRJAN. Relatório do estudo de viabilidade de um pólo de fruticultura na região Norte e Noroeste Fluminense. Rio de Janeiro, 1998. 31 p.

JONES, H. G. Plants and microclimate: a quantitative approach to environmental plant physiology. Cambridge: Cambridge University, 1992. 85 p.

KAISER, C.; ALLAN, P.; WHITE, B. J.; DEHRMANN, F. M. Some morphological aspects of freckle on papaya (Carica papaya L.) fruit. Journal South Africa Society Science, Cidade do Cabo, v. 6, n. 1, p. 37-40, 1996.

LEONARDI, C.; GUICHARD, S.; BERTIN, N. High vapour pressure deficit influences growth, transpiration and quality of tomato fruits. Scientia Horticulturae, Amsterdam, v. 84, p. 285-296, 2000.

LIMA, H. C. Relações entre o estado nutricional, as variáveis do clima e a incidência da mancha fisiológica do mamão (Carica papaya L.) no Norte Fluminense. 2002. 60 f. Dissertação (Mestrado) - Universidade Estadual do Norte Fluminense, Campos dos Goytacazes, 2002.

OHTA, K.; HOSOKI, T.; MATSUMOTO, K.; OHYA, M.; ITO, N.; INABA, K. Relationship between fruit cracking and changes of fruit diameter associated with solute flow to fruit in cherry tomatoes. Journal of Japanese Society for Horticultural Science, Kyoto, v. 65, p. 753-759, 1997.

PAULL, R. E.; CHEN, N. J. Waxing and plastic wraps influence water loss from papaya fruit during storage and ripening. Journal American Society Horticultural Science, Alexandria, v. 114, p. 937-942, 1989.

PAARDEKOOPER, E. C.; SOOKMARK, S. Diurnal variation in latex yield. Journal Rubber Research Institute Malaya, Kuala Lumpur, v. 21, p. 341-347, 1969.

RAGHAVENDRA, A. S. Latex exudation from rubber tree, Hevea brasiliensis. In: Physiology of trees. New York: J. Wiley \& Sons, 1991. p. 403-417.

REYES, M. E. Q.; PAULL, R. E. Skin freckles on solo papaya fruit. Scientia Horticulturae, Amsterdam, v. 58, p. 31-39, 1994.

UENO, B.; NEVES, E. F.; MACHADO FILHO, J. A.; YAMANISHI, O. K.; FAGUNDES, G. R.; CAMPOSTRINI, E. Mancha fisiológica em frutos de mamoeiro no oeste da Bahia: relatório de trabalho da parceria Universidade de Brasília com os produtores de mamão da Associação dos Irrigantes do Oeste da Bahia (AIBA). Brasília, DF, 2002. 109 p 